\title{
Blunting of insulin-mediated proteolysis in leg muscle of elderly subjects may contribute to age-related sarcopenia
}

\author{
E. Wilkes, A. Selby, R. Patel, D. Rankin, K. Smith and M. Rennie \\ University of Nottingham, School of Graduate Entry Medicine \& Health, Derby DE22 3DT, UK
}

\begin{abstract}
Sarcopenia is common in the elderly, with a loss of muscle mass of $0.5-2 \%$ year after 50 years of age ${ }^{(1)}$. However, although the mechanisms must involve some disturbance of the normal processes of maintenance of muscle protein, available data suggest that basal post-absorptive muscle protein synthesis (MPS) is not decreased and muscle protein breakdown (MPB) not elevated. However, it has been shown previously that the response of MPS to essential amino acids is less sensitive and of lower capacity in elderly men (approximately 70 years of age) than in young men (approximately 25 years of age). Now the hypothesis has been tested that the normal insulin-mediated blunting of MPB, which accompanies feeding, is blunted in elderly subjects compared with younger subjects. Five young subjects (three men, two women, age 19-33 years, BMI $24 \mathrm{~kg} / \mathrm{m}^{2}$ ) and eight elderly subjects (four men, four women, age $61-72 \mathrm{years}$, BMI $26 \mathrm{~kg} / \mathrm{m}^{2}$ ) were studied in the post-absorptive state. Cannulas were inserted to allow sampling of arterialized hand blood and femoral venous blood and infusion of $\left[1,2-{ }^{13} \mathrm{C}\right]$ leucine and $\left[{ }^{2} \mathrm{H}_{5}\right]$ phenylalanine $(0.75 \mathrm{mg} / \mathrm{kg}$ prime, $1.0 \mathrm{mg} / \mathrm{kg} \mathrm{perh} \mathrm{and} 0.3 \mathrm{mg} / \mathrm{kg} \mathrm{prime}, 0.6 \mathrm{mg} / \mathrm{kg} \mathrm{perh}$ respectively). Blood flow in the femoral artery was measured by Doppler ultrasound. Insulin and octreotide were infused to achieve plasma insulin concentrations at approximately $4 \mathrm{mU} / \mathrm{l}$ and approximately $15 \mathrm{mU} / \mathrm{l}$ respectively, each for $1.5 \mathrm{~h}$. Glucose was infused to maintain euglycaemia (approximately $5 \mathrm{~mm}$ ) together with sufficient mixed amino acids (AA; Glamin; Fresenius, Runcorn, Cheshire, UK) to allow maintenance of the post-absorptive plasma AA concentration. Leg exchange of leucine, phenylalanine and unlabelled AA were measured using GC-MS and ion-exchange chromatography at both insulin concentrations. In all subjects the post-absorptive state was characterized by a net efflux of AA, as a result of the predominance of MPB over MPS. In the young subjects infusion of insulin to approximately $15 \mathrm{mU} / \mathrm{l}$ reduced MPB by approximately $60 \%$ from 296 (SD 47) nmol leucine/100 $\mathrm{ml}$ leg per min $(P<0.01)$ and by approximately $52 \%$ from 97.5 (SD 14.2) nmol phenylalanine/100 ml leg per min. However, in the elderly this effect was markedly blunted, the suppression from 153 (SD 30) nmol leucine/100 ml leg per min and 70.2 (SD 11.6) nmol phenylalanine/100 ml leg per min not reaching statistical significance in either case. Thus, it appears that insulin-induced suppression of MPB is blunted in the elderly, which may contribute to the progressive inability of older individuals to maintain their muscle mass.
\end{abstract}

Supported by UK BBSRC and the EC EXEGENESIS programme.

1. Frontera WR, Hughes VA, Fielding RA, Fiatarone MA, Evans WJ \& Roubenoff R (2000) J Appl Physiol 88, 1321-1326.

2. Cuthbertson D, Smith K, Babraj J, Leese G, Waddell T, Atherton P, Wackerhage H, Taylor PM \& Rennie MJ (2005) FASEB J 19, 422-424 (Epublication 13 Dec 2004). 